ARTICLE

DOI: $10.1038 / \mathrm{s} 41467-017-00383-0 \quad$ OPEN

\title{
Ultra-large single crystals by abnormal grain growth
}

Tomoe Kusama1, Toshihiro Omori ${ }^{1}$, Takashi Saito ${ }^{1}$, Sumio Kise ${ }^{2}$, Toyonobu Tanaka², Yoshikazu Araki $^{3} \&$ Ryosuke Kainuma ${ }^{1}$

Producing a single crystal is expensive because of low mass productivity. Therefore, many metallic materials are being used in polycrystalline form, even though material properties are superior in a single crystal. Here we show that an extraordinarily large $\mathrm{Cu}-\mathrm{Al}-\mathrm{Mn}$ single crystal can be obtained by abnormal grain growth (AGG) induced by simple heat treatment with high mass productivity. In AGG, the sub-boundary energy introduced by cyclic heat treatment $(\mathrm{CHT})$ is dominant in the driving pressure, and the grain boundary migration rate is accelerated by repeating the low-temperature $\mathrm{CHT}$ due to the increase of the sub-boundary energy. With such treatment, fabrication of single crystal bars $70 \mathrm{~cm}$ in length is achieved. This result ensures that the range of applications of shape memory alloys will spread beyond small-sized devices to large-scale components and may enable new applications of single crystals in other metallic and ceramics materials having similar microstructural features.

\footnotetext{
${ }^{1}$ Department of Materials Science, Graduate School of Engineering, Tohoku University, Aoba-yama 6-6-02, Sendai, Miyagi 980-8579, Japan. ${ }^{2}$ Technology Development Department, Special Metals Division, Furukawa Techno Material Co., Ltd., 5-1-8 Higashi-yawata, Hiratsuka, Kanagawa 254-0016, Japan.

${ }^{3}$ Department of Architecture and Architectural Engineering, Graduate School of Engineering, Kyoto University, Katsura, Nishikyo, Kyoto 615-8540, Japan.

Correspondence and requests for materials should be addressed to T.O. (email: omori@material.tohoku.ac.jp)
} 
$\mathrm{M}$ ost metals, semiconductors and ceramics are composed of a large number of crystals, i.e., polycrystalline structure. Although some kinds of materials including not only semiconductors and ceramics but also shape memory alloys $^{1-6}$ and heat-resistant alloys ${ }^{7-9}$ show superior properties in single crystalline form, the use of single crystals is, however, restricted to some special applications due to the high cost of processing. Single crystals are normally fabricated by crystal growth methods during solidification, such as the Bridgman process and the Czochralski processes ${ }^{10-12}$. Another possibility for single crystal production is a solid-state technique utilizing abnormal grain growth (AGG). In polycrystalline materials, grain growth occurs to reduce the fraction of grain boundaries (GBs) with high energy, in which the grain structure coarsens by gradual growth of larger grains and elimination of smaller ones ${ }^{13}$. The distribution of grain size is relatively uniform during normal grain growth (NGG). In certain circumstances, only limited grains consume the surrounding smaller grains and grow rapidly, which is called $\mathrm{AGG}^{13-15}$. Several methods to obtain a single crystal using AGG in a solid state have been reported, one of the most well-known methods being the strain-anneal method using slight cold-deformation followed by thermal annealing ${ }^{16,17}$.

Very recently, the present authors reported a new AGG phenomenon in the $\beta$ (bcc: body centered cubic) phase induced by cyclic heat treatment (CHT) through $\beta / \beta+\alpha$ (fcc: face centered cubic) phase transformation in $\mathrm{Cu}-\mathrm{Al}-\mathrm{Mn}$ shape memory alloy ${ }^{18}$. This technique is highly advantageous for obtaining a single crystal. In general, when abnormally growing

a

HTC

LTC
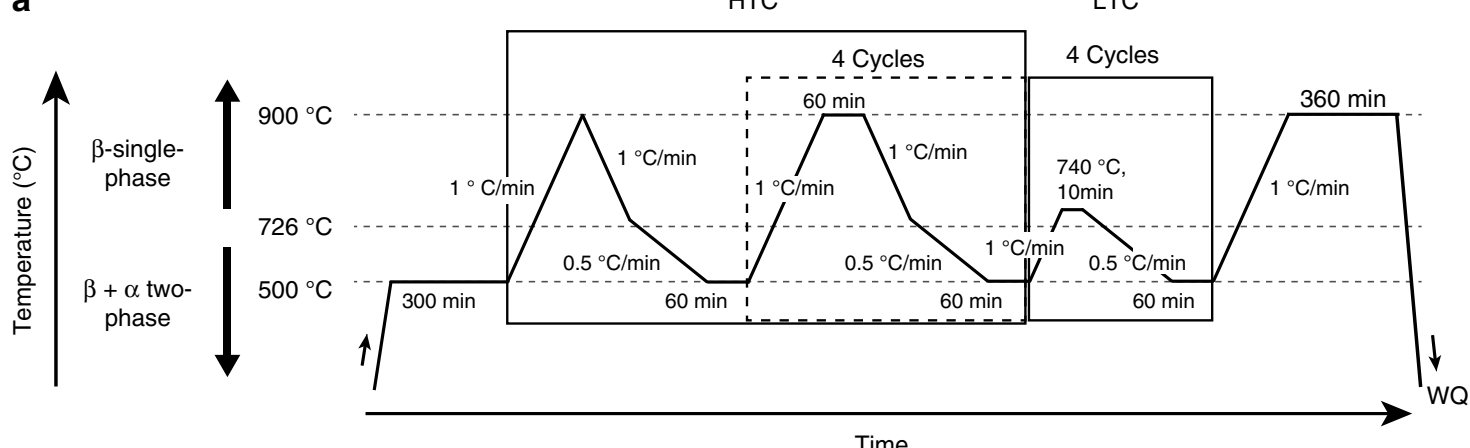

b

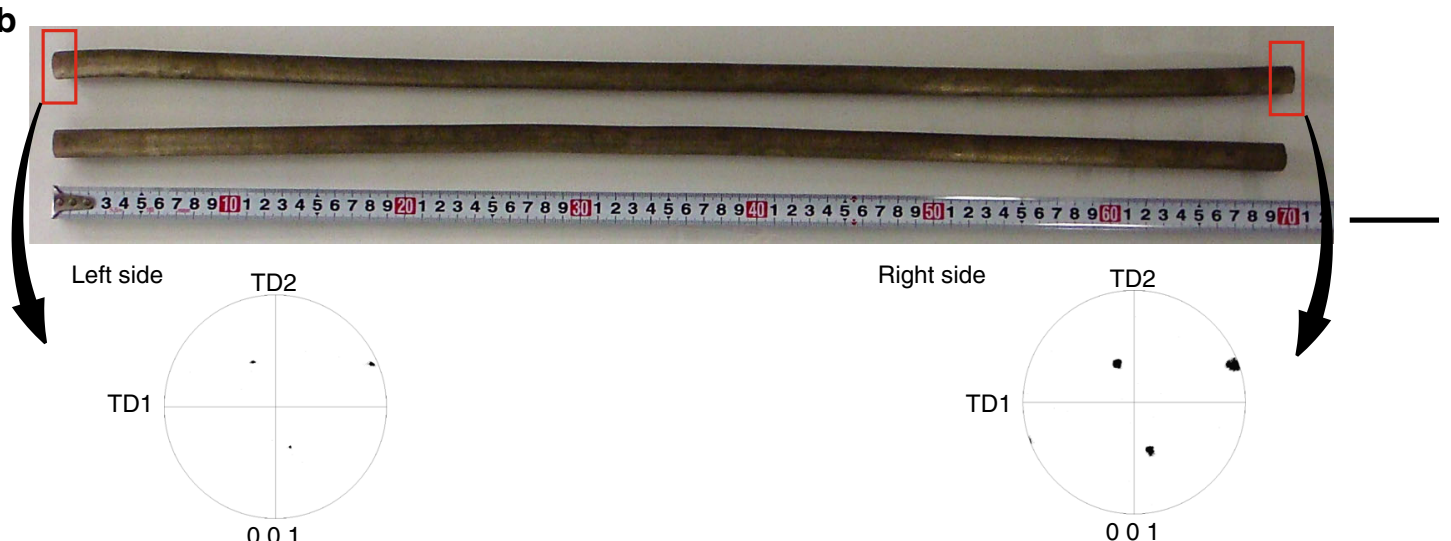

C

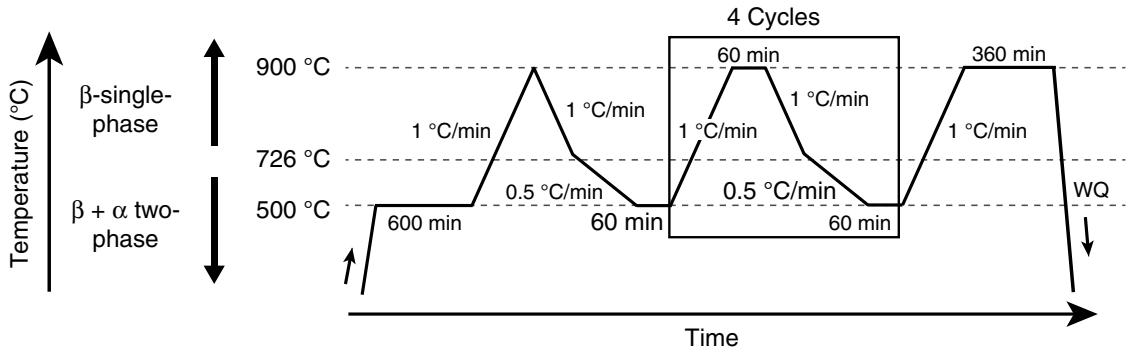

d

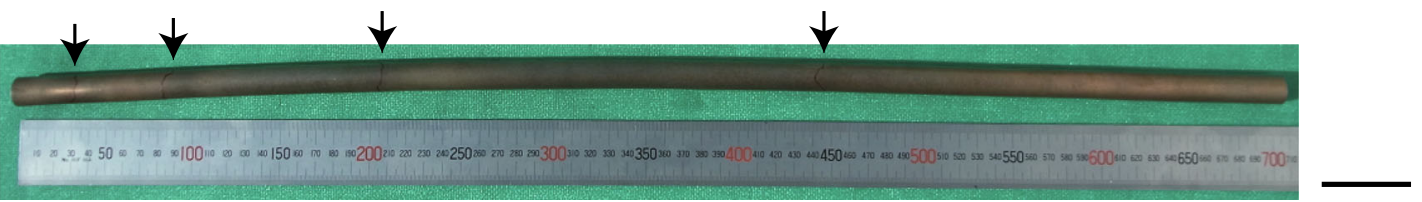

Fig. 1 Single crystal and oligocrystalline Cu-Al-Mn shape memory alloy bars. a Diagram of cyclic heat treatment (CHT) with a combination of the high-temperature cycle (HTC) and low-temperature cycle (LTC) for obtaining a single crystal (WQ: water quenching). b Cu-Al-Mn single crystal bars $15 \mathrm{~mm}$ in diameter and $700 \mathrm{~mm}$ in length obtained by the CHT shown in Fig. 1a, and (001) pole figures at the both ends of the bar, which show that the crystal orientations at the both ends are almost the same. Scale bar, $50 \mathrm{~mm}$. c Diagram of HTC without LTC. d Cu-Al-Mn alloy bar with a bamboo structure $15 \mathrm{~mm}$ in diameter and $700 \mathrm{~mm}$ in length, subjected to CHT shown in Fig. 1c. The maximum length of a crystallographic grain is about $250 \mathrm{~mm}$ and some grain boundaries, as indicated by arrows, are always detected in the bar specimens after this treatment. Scale bar, $50 \mathrm{~mm}$ 
a

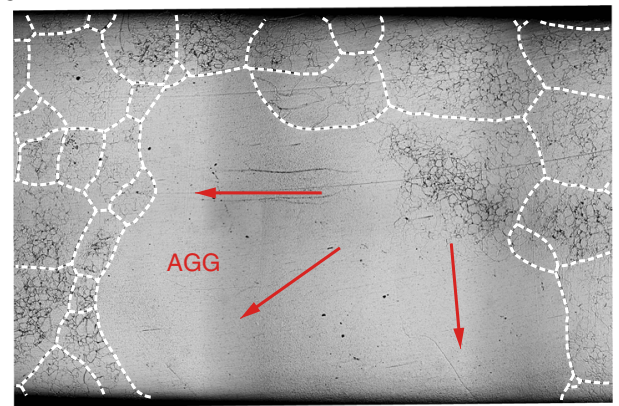

b
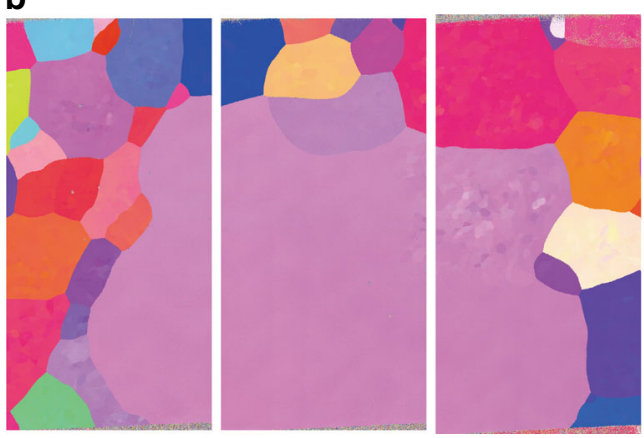

C
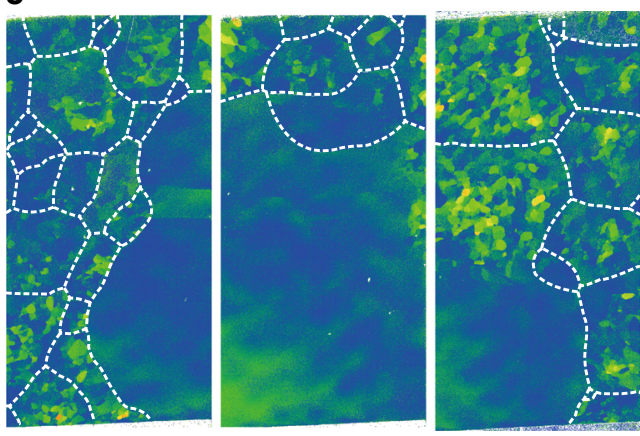

\section{$0^{\circ}$}
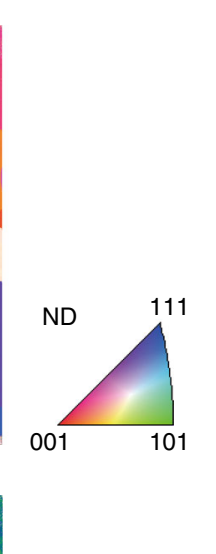

1

since they can dissipate energy by stress-strain hysteresis, recover deformation upon unloading and limit force transmission ${ }^{19}, 20$. Ti-Ni shape memory alloy bars showing self-centering capability due to superelasticity are being used on a trial basis as a part of bridge columns to reduce permanent deformation by earthquakes $^{21}$. However, the low machinability and coldworkability of the conventional $\mathrm{Ti}-\mathrm{Ni}$ alloy are obstacles to its widespread use. Since $\mathrm{Cu}-\mathrm{Al}-\mathrm{Mn}$ shape memory alloys have high machinability and cold-workability 22 , their application to seismic devices has been investigated ${ }^{23-25}$. The superelasticity of $\mathrm{Cu}$-based shape memory alloys is drastically enhanced by increasing the grain size relative to the cross-sectional size of materials $^{{ }^{1-3}}$, and in particular, an ideal superelastic response can be obtained in a single crystal ${ }^{26-28}$. If the fabrication of large single crystal parts can be realized by simple heat-treatment, applications to seismic devices are expected to increase.

In the present study, the mechanism of the AGG induced by $\mathrm{CHT}$ in a $\mathrm{Cu}-\mathrm{Al}-\mathrm{Mn}$ alloy is investigated by microstructural analysis. GBs migrate consuming the subgrains formed during the $\mathrm{CHT}$, leading to AGG, and the growth rate increases with increasing the misorientation between the subgrains. These facts suggest that the sub-boundary energy is a driving pressure of AGG, which is supported by the thermodynamic analysis. Based on this mechanism, a heating/cooling process, including low-temperature CHT between 740 and $500{ }^{\circ} \mathrm{C}$, is developed for accelerated AGG, and as a result, fabrication of single crystal bars $700 \mathrm{~mm}$ in length is achieved by only CHT.

\section{Results}

Grain growth to single crystal. In the present $\mathrm{Cu}_{71.6} \mathrm{Al}_{17} \mathrm{Mn}_{11.4}$ (at\%) alloy, the $\beta$ single phase is stable at temperatures higher than $726^{\circ} \mathrm{C}$ and the $\alpha$-phase precipitates at lower temperatures ${ }^{18}, 29$. We conducted five heating/cooling cycles between 900 and $500{ }^{\circ} \mathrm{C}$ (high-temperature cycle: HTC), four cycles between 740 and $500^{\circ} \mathrm{C}$ (low-temperature cycle: LTC), and final heating to $900{ }^{\circ} \mathrm{C}$, as shown in Fig. 1a. Figure $1 \mathrm{~b}$ shows $\mathrm{Cu}-\mathrm{Al}-\mathrm{Mn}$ bars with a dimension of $15 \mathrm{~mm} \phi \times 700 \mathrm{~mm}$ subjected to the CHT of Fig. 1a. No GB is observed (except sub-boundaries) in the bars and both ends have almost the same orientation, as shown in the (001) pole figure, meaning that a single crystal $700 \mathrm{~mm}$ in length was obtained by the combination of HTC and LTC. On the other hand, in the $\mathrm{Cu}-\mathrm{Al}-\mathrm{Mn}$ bar obtained when skipping the LTC treatment (Fig. 1c), several GBs always remained, as shown in Fig. $1 \mathrm{~d}$.

Microstructures. In order to understand this AGG phenomenon, we investigated the microstructure of the $\mathrm{Cu}-\mathrm{Al}-\mathrm{Mn}$ alloy after CHT. Figure $2 \mathrm{a}-\mathrm{c}$ shows an optical micrograph, inverse pole figure (IPF) mapping and grain reference orientation deviation (GROD) mapping, respectively, in a $\mathrm{Cu}-\mathrm{Al}-\mathrm{Mn}$ alloy immediately quenched from $900^{\circ} \mathrm{C}$ without annealing after one HTC. As shown in the micrograph and mappings, abnormal grains (AGs) are surrounded by smaller grains containing a high density of subgrains with orientation deviation within $\sim 3^{\circ}$ to the neighboring subgrains. It is important to note that in the AG as well, the subgrain structure is locally observed in the upper-right region. A similar microstructure was detected in many other AGs in the alloy. This fact strongly suggests that the GBs of the AGs migrate, sweeping out the surrounding grains with subgrains, as indicated by red arrows in Fig. 2 a.

This microstructural evolution is depicted in the schematic illustration of Fig. 3a. All the $\beta$-grains initially contain some density of subgrains which were introduced by the precipitation of the $\alpha$-phase, as reported in our previous paper ${ }^{18}$, and the pre-existing GBs are in contact with the subgrains on both sides 

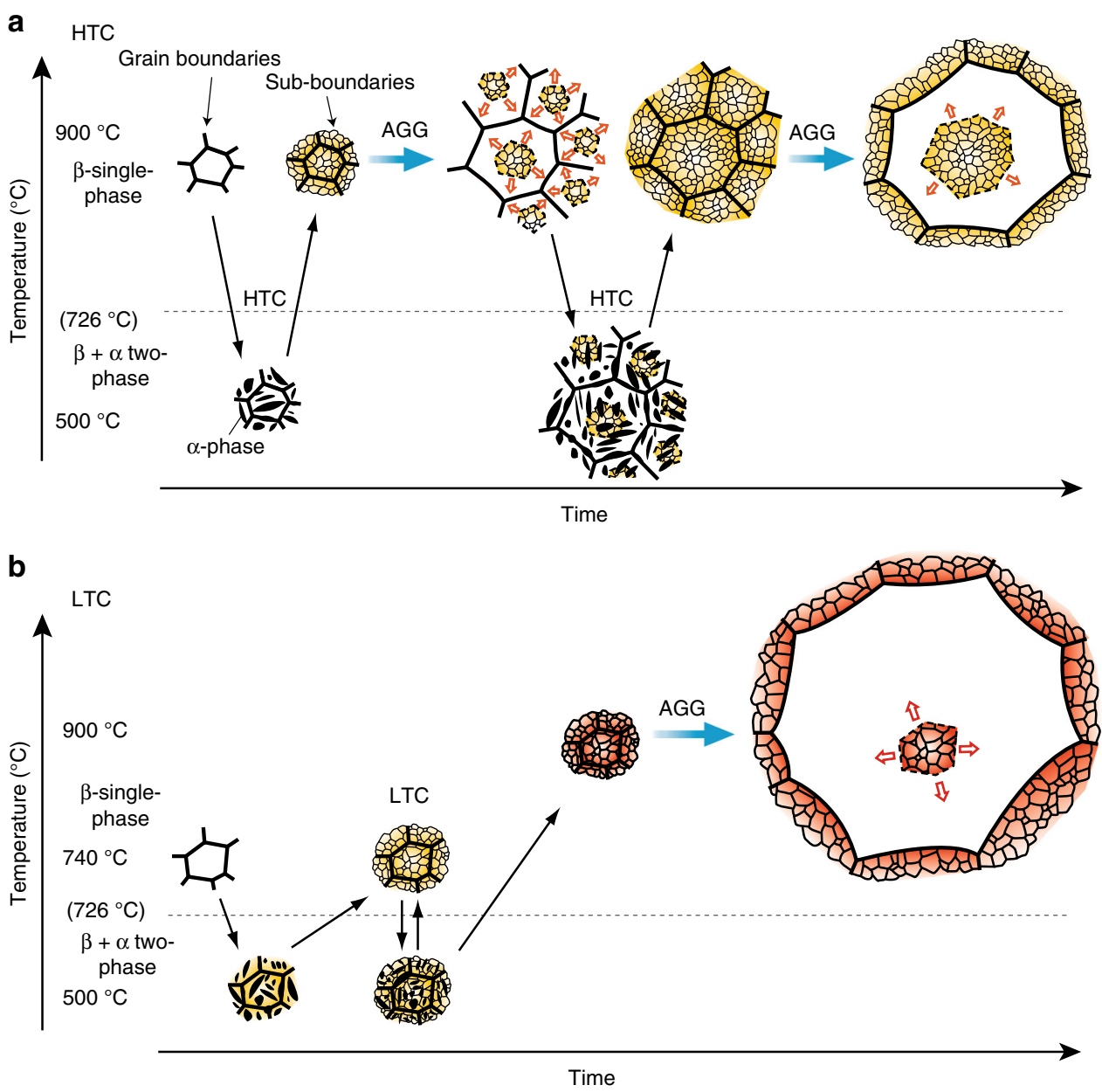

Fig. 3 Schematic illustrations of abnormal grain growth (AGG) phenomenon. a In high-temperature cycles (HTC) $\left(900 / 500^{\circ} \mathrm{C}\right.$ ), the subgrain structure formed in association with $\alpha$-phase precipitation at $500^{\circ} \mathrm{C}$ remains after resolution of $\alpha$-phase in heating. At $900{ }^{\circ} \mathrm{C}$ after $\mathrm{HTC}$, some grains start $\mathrm{AGG}$ by consuming the surrounding subgrains, and this continues until the abnormal grain (AG) comes in contact with a neighboring $A G$, where the dominant driving pressure for grain boundary (GB) migration is the sub-boundary energy. AGG can repeatedly occur if HTC is repeated. $\mathbf{b}$ In multiple low-temperature cycles (LTCs) $\left(740 / 500^{\circ} \mathrm{C}\right)$, the sub-boundary energy increases due to the increasing misorientation between subgrains. As a result, the $\mathrm{GB}$ migration rate at $900^{\circ} \mathrm{C}$ becomes faster and a super-large crystal can be realized

in the initial stage. When one grain occasionally starts to grow as NGG (Supplementary Discussion), a subgrain-free zone is formed only behind the moving GB. Since the GBs migrate consuming the sub-boundaries existing only in front of the moving $\mathrm{GB}$, the growth rate of the grain becomes faster and the normal grain $(\mathrm{NG})$ may change to an AG. That is, the boundary energy of subgrains may be one component of the driving pressure in the present AGG phenomenon. When the AGs growing in several regions come in contact with one another, AGG may be temporarily arrested due to the loss of driving pressure. The subgrain structure, however, can be restored by further $\mathrm{CHT}$ and AGG recommences. Thus, AGG can additionally be induced by repeating $\mathrm{CHT}$ and a large crystal can be consequently obtained.

Grain boundary migration rate. To quantitatively discuss this proposed mechanism of AGG, we experimentally estimated the growth rate of AGs, which encroached on the subgrains in some $\mathrm{Cu}-\mathrm{Al}-\mathrm{Mn}$ alloy sheets with different subgrain microstructures. The first set of sheets was cooled from 800 to $500{ }^{\circ} \mathrm{C}$ and then heated to $800{ }^{\circ} \mathrm{C}$ (one middle-temperature cycle: MTC), followed by holding for different periods. Another set of specimens was subjected to cycles between 500 and $740{ }^{\circ} \mathrm{C}$ five times (five LTCs) and then heated to $800{ }^{\circ} \mathrm{C}$, followed by holding for different periods. It should be noted that no AGG occurs at $740{ }^{\circ} \mathrm{C}$. Here, the MTC at $800^{\circ} \mathrm{C}$, but not the HTC at $900^{\circ} \mathrm{C}$, was selected for this examination because the AGG induced by the HTC is too fast to trace the microstructural change. As shown in the optical micrographs in Fig. $4 \mathrm{a}, \mathrm{b}$, no $\mathrm{AG}$ is seen in the sheet without holding, but abnormally growing grains appear in the samples held at $800^{\circ} \mathrm{C}$. The migration distance of the AGs is plotted in Fig. $4 \mathrm{c}$ as a function of annealing time at $800^{\circ} \mathrm{C}$, together with the data of NGG by isothermal annealing at $900^{\circ} \mathrm{C}^{30}$. The migration distance of the AGs obtained by isothermal annealing at $800{ }^{\circ} \mathrm{C}$ after one MTC is larger by two orders of magnitude than that in the NGG at $900^{\circ} \mathrm{C}$. It is also obvious from Fig. $4 \mathrm{c}$ that the migration distance of the AGs in specimens annealed at $800^{\circ} \mathrm{C}$ after five LTCs is greater than that in the specimens after one MTC. The GB migration rate after one MTC and five LTCs estimated from the initial slope of each line is $1.6 \times 10^{-5}$ and $8.7 \times 10^{-5} \mathrm{~m} \mathrm{~s}^{-1}$, respectively.

The GROD mappings and misorientation angle analyzed by electron backscatter diffraction (EBSD) for one LTC and five LTCs are shown in Fig. 4d, e, respectively. It is found that the orientation spread in grains due to the subgrain microstructure becomes larger with an increasing number of 
LTCs. These facts suggest that the sub-boundary energy, depending on the misorientation angle between subgrains, is an important component of the driving pressure in the present AGG. Note that AGG is a phenomenon in which a few large grains rapidly grow in a stagnating fine grained matrix, the GB migration being driven by the capillarity forces due to $\mathrm{GB}$ curvature $^{13}$. The grain growth reported in this paper is different from the previously accepted AGG with regard to the driving force. It should also be mentioned that dislocations possibly exist within grains, which can more or less contribute to the driving force of AGG, although it is difficult to quantitatively evaluate it here.

\section{Discussion}

Here, we estimate the growth rate of an AG based on the proposed mechanism and compare it with the experimental results shown in Fig. 4. The growth rate of a grain with radius $R$ is given using GB mobility, $M^{g b}$, and the driving pressure, $\Delta G$, by ${ }^{15,31}$

$$
\frac{\mathrm{d} R}{\mathrm{~d} t}=M^{g b} \cdot \Delta G
$$

The driving pressure for the present AGG is divided into two components: the sub-boundary energy stored in the subgrain structure $\left(\Delta G_{s}\right)$ and the driving pressure due to the pre-existing a

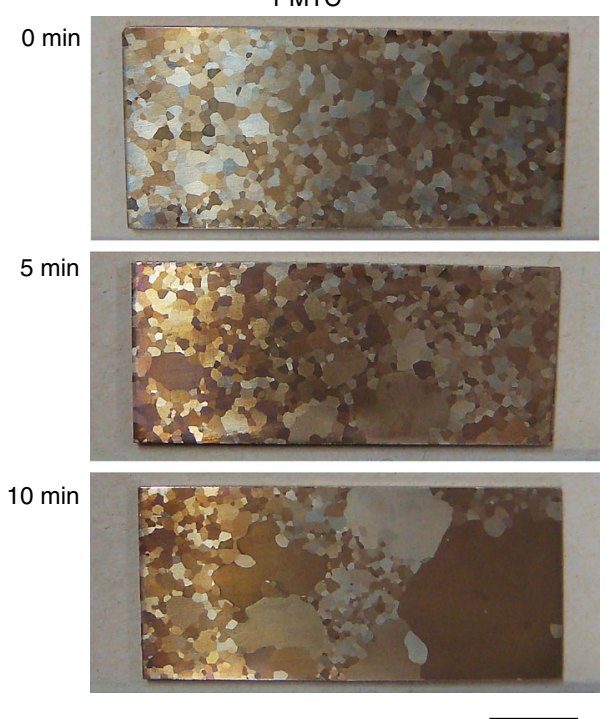

b

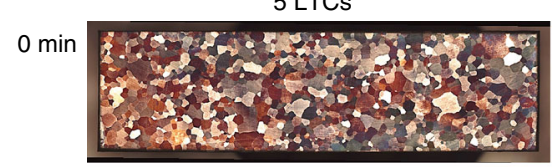

$2 \min$

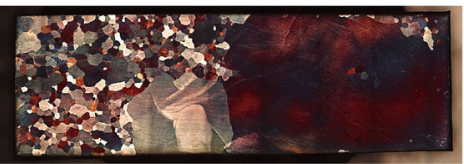

$10 \mathrm{~min}$

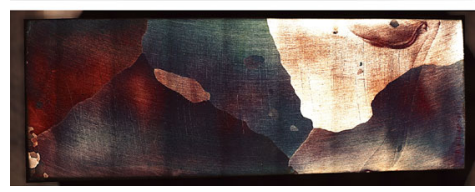

C

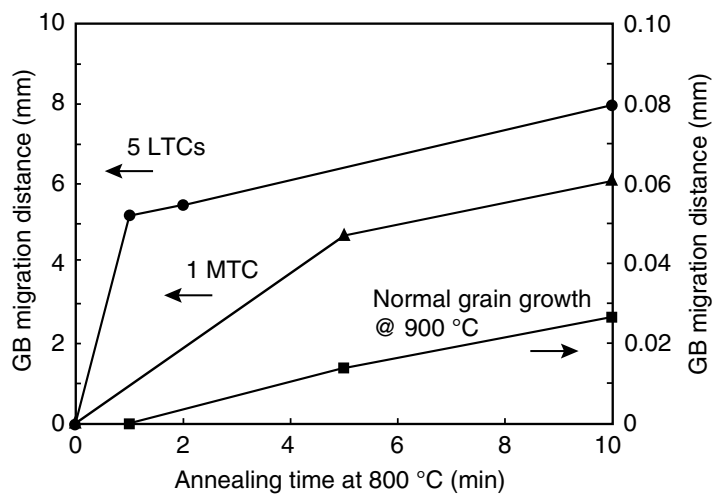

d
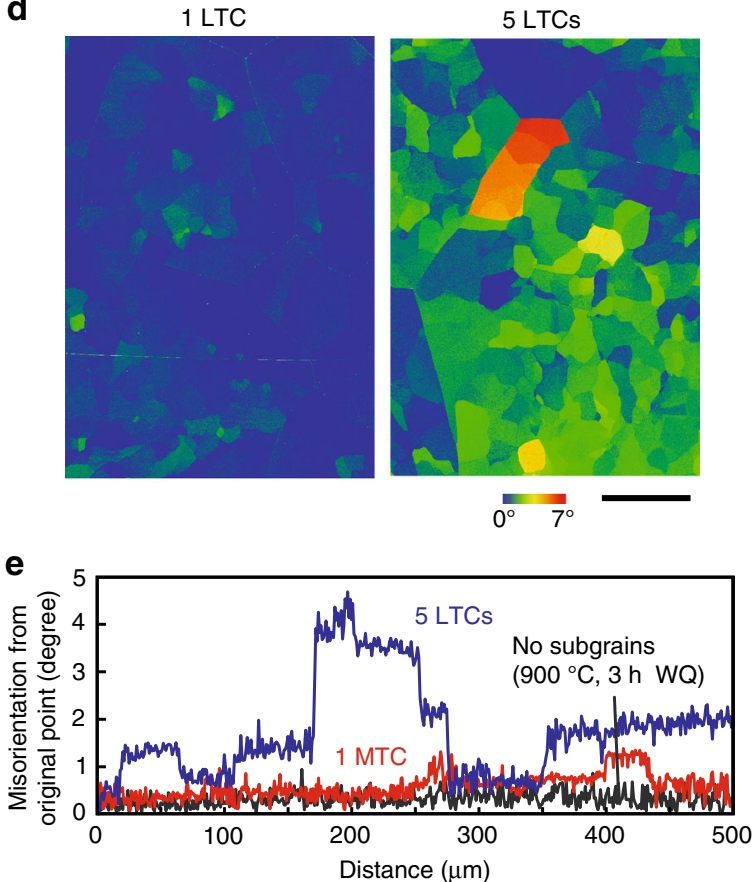

Fig. 4 Grain boundary (GB) migration distance and subgrain structure. a Microstructure of Cu-Al-Mn sheets subjected to one middle-temperature cycle (MTC) (800-500-800 ${ }^{\circ} \mathrm{C}$ ) followed by quenching after continuous holding at $800^{\circ} \mathrm{C}$ for different periods from 0 to 10 min (Supplementary Fig. $4 \mathrm{~b}$ ). Scale bar, $5 \mathrm{~mm}$. b Microstructure subjected to five low-temperature cycles (LTCs) $\left(740-500-740^{\circ} \mathrm{C}\right)$ and heated to $800^{\circ} \mathrm{C}$, followed by quenching after holding for different periods from 0 to $10 \mathrm{~min}$ (Supplementary Fig. 4c). Scale bar, $5 \mathrm{~mm}$. c GB migration distance experimentally determined for abnormal grain (AG) shown in Fig. 4a, b obtained after one MTC and five LTCs (Supplementary Fig. 4b, c) as a function of annealing time at $800{ }^{\circ} \mathrm{C}$ in Cu-Al-Mn alloy. GB migration distance in the normal grain growth (NGG) mode by isothermal heat treatment at $900{ }^{\circ} \mathrm{C}$ is also shown for comparison ${ }^{31}$. $\mathbf{d}$ Grain reference orientation deviation (GROD) mapping for specimen subjected to one LTC (Supplementary Fig. 4d) and five LTCs (Supplementary Fig. 4e). It is obvious that the orientation mismatch among subgrains after five LTCs is larger than that after one LTC. Scale bar, $200 \mu \mathrm{m}$. e Misorientation from original point in one LTC (Supplementary Fig. 4d) and five LTC (Supplementary Fig. 4e) specimens of Cu-Al-Mn alloy. Data without subgrains are also shown for reference. The background is about $0.5^{\circ}$. Orientation gaps smaller than $1^{\circ}$, corresponding to a sub-boundary, are detected in one LTC specimen, but gaps up to $2.5^{\circ}$ are more clearly observed in five LTC specimen 


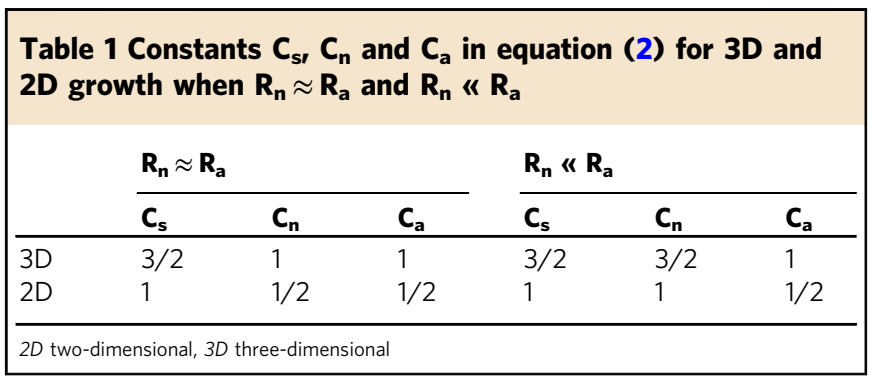

grains with high-angle boundary $\left(\Delta G_{\mathrm{h}}\right)$, as given in the following equation: ${ }^{13}$

$$
\begin{aligned}
\Delta G_{\mathrm{total}} & =\Delta G_{\mathrm{s}}+\Delta G_{\mathrm{h}} \\
& =\frac{C_{S} \sigma_{\mathrm{s}} V_{\mathrm{m}}}{R_{S}}+\sigma_{\mathrm{h}} V_{\mathrm{m}}\left(\frac{C_{n}}{R_{n}}-\frac{C_{a}}{R_{a}}\right),
\end{aligned}
$$

where $\sigma_{s}$ and $\sigma_{h}$ are the GB energies of a subgrain and a high-angle pre-existing grain (a NG or an AG) boundaries, $R_{s}, R_{n}$ and $R_{a}$ are the mean radii of subgrains and NGs and the radius of an $\mathrm{AG}$, and $V_{\mathrm{m}}$ is the molar volume, respectively. $C_{s}, C_{n}$ and $C_{a}$ are constants, depending on the growing dimension, and are listed in Table 1 . The $V_{\mathrm{m}}$ of Cu-Al-Mn is $7.6 \times 10^{-6} \mathrm{~m}^{3} \mathrm{~mol}^{-132}$, and $\sigma_{h}=0.595 \mathrm{~J} \mathrm{~m}^{-2}$ for $\mathrm{Cu}-30 \mathrm{Zn}^{33}$ is used here. The GB energy of a subgrain $\sigma_{S}$ can be estimated by the following Read-Shockley equation with the misorientation, $\theta^{34}$ :

$$
\sigma_{s}=\sigma_{\mathrm{h}} \frac{\theta}{\theta_{\mathrm{h}}}\left(1-\ln \frac{\theta}{\theta_{\mathrm{h}}}\right),
$$

where $\theta_{\mathrm{h}}\left(=15^{\circ}\right)$ is the critical angle of a low-angle boundary, and at $\theta>\theta_{\mathrm{h}}$ the boundary becomes a high-angle GB with boundary energy, $\sigma_{\mathrm{h}}\left(=\sigma_{\mathrm{s}}\right.$ at $\left.\theta=15^{\circ}\right)$. From the EBSD analysis (Supplementary Fig. 1), the average $\theta$ is $0.46^{\circ}$ and $1.12^{\circ}$ for one LTC and five LTCs, respectively. Using $\sigma_{\boldsymbol{h}}=0.595 \mathrm{~J} \mathrm{~m}^{-2}$ appropriate for $\mathrm{Cu}-30 \mathrm{Zn}^{33}$, because of lack of data of $\mathrm{Cu}-\mathrm{Al}-\mathrm{Mn}$ alloy, $\sigma_{s}$ is calculated to be $8.18 \times 10^{-2} \mathrm{~J} \mathrm{~m}^{-2}$ after one MTC and $1.60 \times 10^{-1} \mathrm{~J} \mathrm{~m}^{-2}$ after five LTCs. The $R_{s}$ can be assumed to be constant $\left(R_{s}=30 \mu \mathrm{m}\right.$ for one MTC and $R_{S}=24 \mu \mathrm{m}$ for five LTCs) because the growth rate is extremely low, as shown in Supplementary Fig 2. While the $R_{n}$ and $R_{a}$ are time-dependent, for the initial state $\left(R_{n} \cong R_{a}\right)$, only the first term in Eq. 2 is taken into account and the driving pressure after one MTC and five LTCs are $\Delta G_{s}=3.1 \times 10^{-2} \mathrm{~J} \mathrm{~mol}^{-1}$ and $7.6 \times 10^{-2} \mathrm{~J} \mathrm{~mol}^{-1}$, respectively. It is important that this driving pressure due to sub-boundaries hardly decreases by annealing because of the very low growth rate of subgrains (Supplementary Fig. 2). When the AGG progresses, the second term must also be considered, and using $R_{n}=400 \mu \mathrm{m}$ and $R_{a} \approx \infty$, the driving pressure after one MTC and that after five LTCs are $\Delta G_{\text {total }}=4.8 \times 10^{-2} \mathrm{~J} \mathrm{~mol}^{-1}$ and $9.3 \times 10^{-2} \mathrm{~J} \mathrm{~mol}^{-1}$, respectively, which are the largest estimations of the driving pressure. The difference in the driving pressure between $\Delta G_{\mathrm{s}}$ and $\Delta G_{\text {total }}$ is small (Table 2). This means that the dominant driving pressure for the present AGG phenomenon is the subgrain energy and that the driving pressure is much larger than that of other conventional AGG without subgrains.

The GB mobility is given by the following equation: ${ }^{31}$

$$
M^{g b}=\frac{D^{g b}}{\delta R T},
$$

where $D^{g b}, \delta, R$ and $T$ are the GB diffusion coefficient, the GB thickness, gas constant and temperature, respectively. The $D^{g b}$ is empirically evaluated by the next equation ${ }^{31}$ using the melting point, $T_{\mathrm{m}}$ :

$$
D^{g b} \approx 4 \times 10^{-5} \exp \left[-\frac{82}{R}\left(\frac{T_{\mathrm{m}}}{T}\right)\right]
$$

In the present case, $T_{\mathrm{m}}$ is $948^{\circ} \mathrm{C}(1221 \mathrm{~K})$, and thus $D^{g b}$ at $800^{\circ} \mathrm{C}(1073 \mathrm{~K})$ is estimated as being $5.3 \times 10^{-10} \mathrm{~m}^{2} \mathrm{~s}^{-1}$. Using $\delta=5 \times 10^{-10} \mathrm{~m}^{35}, M^{g b}$ is calculated to be $1.2 \times 10^{-4} \mathrm{~mol} \mathrm{~m} \mathrm{~J} \mathrm{~J}^{-1} \mathrm{~s}^{-1}$.

Then the $\mathrm{GB}$ migration rate at $800^{\circ} \mathrm{C}$ is estimated by Eq. 1 as being $3.7 \times 10^{-6}-5.7 \times 10^{-6} \mathrm{~m} \mathrm{~s}^{-1}$ for one MTC and $9.1 \times 10^{-6}-1.1 \times 10^{-5} \mathrm{~m} \mathrm{~s}^{-1}$ for five LTCs. In this estimation, the rate of five LTCs is $1.9-2.4$ times higher than that of one MTC due to higher misorientation of sub-boundaries. A summary of this estimation is listed in Table 2. The growth rate in this estimation is lower than that in the experiments. It is necessary to experimentally obtain detailed data of growth rate, such as by in situ observation. Also, accurate parameters for calculation of such factors as the GB diffusion coefficient are necessary. Nevertheless, the growth rate becomes faster in the five cycled specimens due to higher sub-boundary energy shown by calculation and the experimental results agree with this. Thus, it can be concluded that the sub-boundary energy introduced by CHT dominantly contributes to the present AGG and that the LTCs are important for obtaining a ultra-large AG, as shown in Fig. 1b. A similar effect, i.e. increase in driving pressure due to larger misorientation at sub-boundaries, is not obtained by multiple HTCs because AGG starts at temperatures higher than $800^{\circ} \mathrm{C}$ in every heating process of HTCs and the sub-boundaries are swept by high-angle GBs. The AGG by LTCs is schematically illustrated in Fig. $3 \mathrm{~b}$.

A question may arise as to the subgrains form through the precipitation process. This issue has not been experimentally clarified in this work, but it is believed that the semi-coherency between the matrix and precipitate is related to this phenomenon. It is known that sessile misfit and glissile dislocations exist to accommodate transformation strains of dilatational and shear components, respectively, at the interface between the matrix and precipitate with different structures when they have some specific orientation relationship and when the precipitate grows by the ledge mechanism ${ }^{36-38}$. Such glissile dislocations are probably the source of the sub-boundaries. A large transformation strain is built up when the precipitates grow and the strain should be accommodated by dislocations, resulting in coherency loss. The $\alpha$ precipitate and $\beta$ matrix have the Kurdjumov-Sachs (K-S), Bain or Pitsch orientation relationship with a semicoherent interface in $\mathrm{Cu}-\mathrm{Al}-\mathrm{Mn}^{18}$. When we compare the GROD mapping of $\mathrm{Cu}-\mathrm{Al}-\mathrm{Mn}$ alloy cooled from 900 to $650{ }^{\circ} \mathrm{C}$ and that cooled to $500^{\circ} \mathrm{C}$ (Fig. 5), it is seen that the precipitates grow by decreasing temperature and that the orientation deviation becomes remarkable. This fact supports the supposition that the formation of the subgrains is generated through the loss of coherency. Further research is required to reveal the formation process of the subgrains.

Based on the formation mechanism of the AGG, the CHT process shown in Fig. 1a was designed to obtain a large single crystal. The strategy in the heat cycles is as follows: In the initial stage, five HTCs between 900 and $500{ }^{\circ} \mathrm{C}$ were performed, where the cooling and heating rate should be enough low (Supplementary Discussion and Supplementary Fig. 3). By this process, a bamboo structure was obtained, but the GBs always remained in the long bars over $300 \mathrm{~mm}$, as shown in Fig. 1d. In the final stage, four LTCs between 740 and $500{ }^{\circ} \mathrm{C}$ were applied to obtain a higher driving force, which accelerated the AGG in the bamboo structure. The GB migration rate at $900{ }^{\circ} \mathrm{C}$ after five LTCs and the migration distance for $360 \mathrm{~min}$ were shown to be $2.2 \times 10^{-5}-2.6 \times 10^{-5} \mathrm{~m} \mathrm{~s}^{-1}$ and $466-570 \mathrm{~mm}$, respectively, by calculation. This estimation means that the LTCs can provide a sufficiently high driving force to sweep the remaining GBs 
Table 2 Driving pressures, grain boundary mobility and AGG velocity

\begin{tabular}{|c|c|c|c|c|c|c|}
\hline Heat treatment & $\Delta G_{\mathrm{s}}\left(\mathrm{J} \mathrm{mol}^{-1}\right)$ & $\Delta G_{h}\left(\mathrm{~J} \mathrm{~mol}^{-1}\right)$ & $\Delta G_{\text {total }}\left(\mathrm{J} \mathrm{mol}^{-1}\right)$ & $M_{g b}\left(\mathrm{~mol} \mathrm{~m} \mathrm{~J}^{-1} \mathrm{~s}^{-1}\right)$ & AGG velocity (calc.) $\left(\mathrm{m} \mathrm{s}^{-1}\right)$ & AGG velocity (exp.) $\left(\mathrm{m} \mathrm{s}^{-1}\right)$ \\
\hline$\overline{1 \mathrm{MTC}}$ & $3.1 \times 10^{-2}$ & $1.7 \times 10^{-2}$ & $4.8 \times 10^{-2}$ & $1.2 \times 10^{-4}$ & $3.7 \times 10^{-6}-5.7 \times 10^{-6}$ & $1.6 \times 10^{-5}$ \\
\hline $5 \mathrm{LTCs}$ & $7.6 \times 10^{-2}$ & $1.7 \times 10^{-2}$ & $9.3 \times 10^{-2}$ & $1.2 \times 10^{-4}$ & $9.1 \times 10^{-6}-1.1 \times 10^{-5}$ & $8.7 \times 10^{-5}$ \\
\hline
\end{tabular}

AG abnormal growth, AGG abnormal grain growth, LTC low-temperature cycle, MTC middle-temperature cycle

Driving pressures (due to subgrains $\Delta G_{s}$, pre-existing normal grains with high-angle boundary $\Delta G_{h}$ and their sum $\Delta G_{\text {total }}$ ), grain boundary mobility of $A G M_{g b}$ and $A G G$ velocities in calculation and experiment for one MTC and five LTC specimens, respectively. $\Delta G_{s}$ in five LTC specimen is about two times larger than that in one MTC, and its AGG velocity is higher

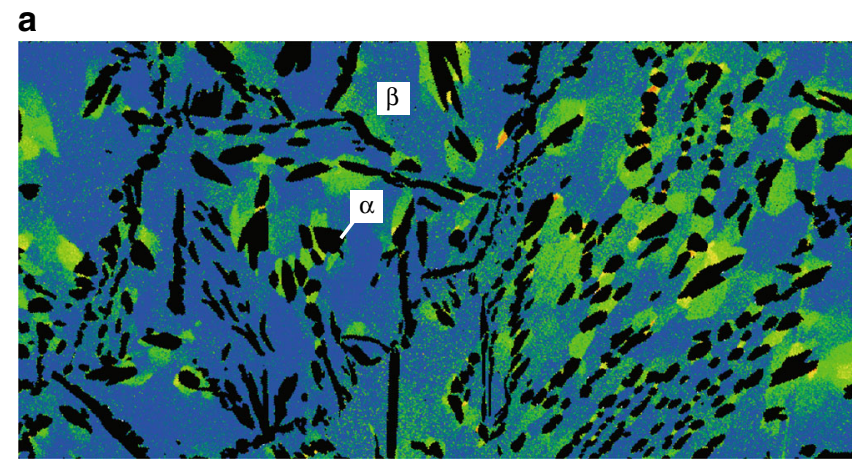

b

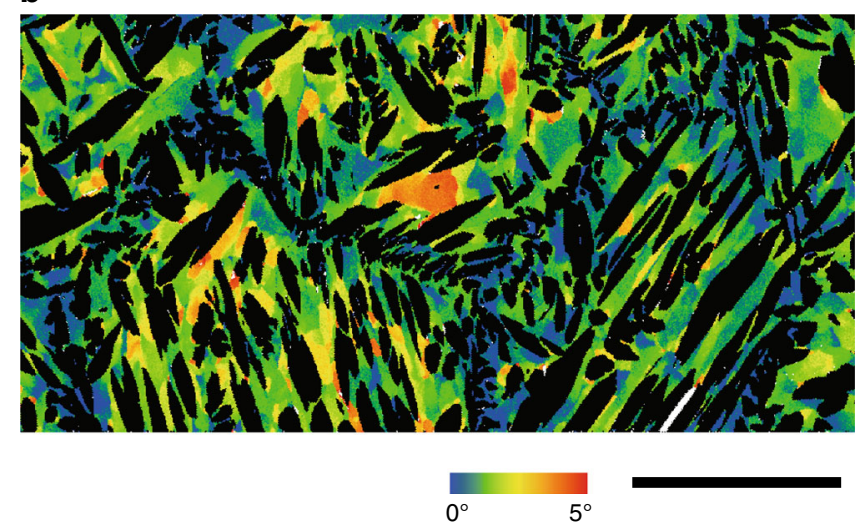

Fig. 5 Microstructure of $\mathrm{Cu}-\mathrm{Al}-\mathrm{Mn}$ alloy subjected to slow cooling to the $\alpha+\beta$ two-phase region. Grain reference orientation deviation (GROD) mapping of $\mathrm{Cu}-\mathrm{Al}-\mathrm{Mn}$ alloy cooled to $\mathbf{a} 650^{\circ} \mathrm{C}$ and $\mathbf{b} 500^{\circ} \mathrm{C}$. Scale bar, $500 \mu \mathrm{m}$. The heat treatment is shown in Supplementary Fig. $4 \mathrm{f}$

out of the long $700 \mathrm{~mm}$ bar, leading to a high possibility of creating a single crystal. As a result, single crystal bars $700 \mathrm{~mm}$ in length and 15 $\mathrm{mm}$ in diameter were obtained, as shown in Fig. 1b. Excellent superelasticity was obtained in the single crystal (Fig. 6 and Supplementary Video 1), while the polycrystalline bar shows large residual strain (Supplementary Video 2).

Since the present technique is advantageous for mass production of single crystals because of the simplicity of the process, this finding opens the way for applications of shape memory single crystals for structural materials, such as for seismic applications in buildings and bridges. Because the AGG related to the subgrain structure has been found in other alloy systems, including in $\mathrm{Cu}-\mathrm{Zn}^{39}, \mathrm{Fe}-\mathrm{Cr}-\mathrm{Co}-\mathrm{Mo}^{40-42}$ and $\mathrm{Fe}-\mathrm{Mn}-\mathrm{Al}-\mathrm{Ni}^{43}, 44$ alloys, this method of single crystal growth in a solid state can be used with other alloy systems that undergo precipitation with semicoherency.

\section{Methods}

Specimen Preparation. Ingots of $\mathrm{Cu}_{71,6} \mathrm{Al}_{17} \mathrm{Mn}_{11,4}$ were prepared by induction melting in an Ar atmosphere for sheet specimens in an $\mathrm{N}_{2}$ atmosphere for bar specimens. Sheet specimens were obtained by hot-rolling at $800^{\circ} \mathrm{C}$ to a thickness

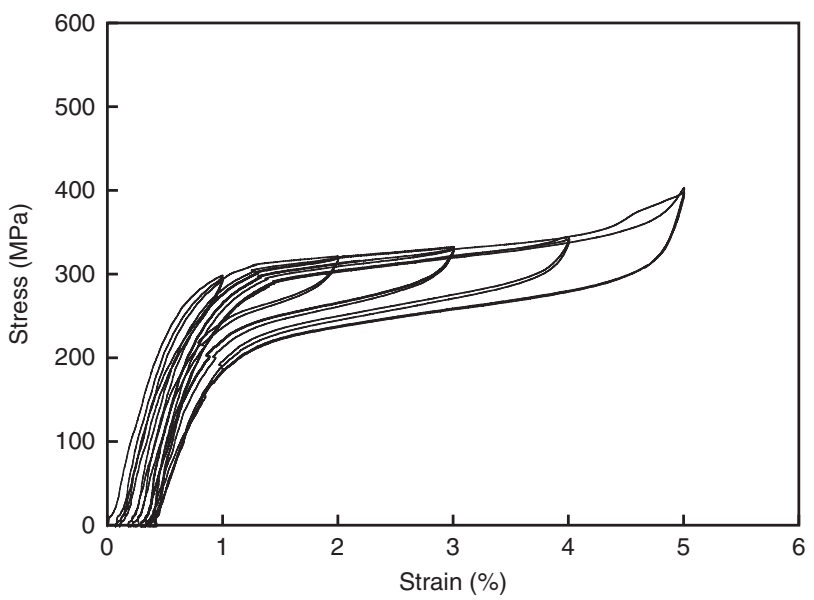

Fig. 6 Tensile superelastic test in Cu-Al-Mn single crystal bar $15.4 \mathrm{~mm}$ in diameter and $682 \mathrm{~mm}$ in length. The target strain was incrementally increased up to $5 \%$. Excellent superelasticity was obtained in the long single crystal bar

of $2 \mathrm{~mm}$ and subsequent cold-rolling to a thickness of $1 \mathrm{~mm}$ with intermediate annealing at $600^{\circ} \mathrm{C}$. Bar specimens were obtained by hot forging and cold drawing to a diameter of $15 \mathrm{~mm}$. The $\beta$ solidus and $\alpha$ solvus temperatures of this alloy were determined to be 948 and $726^{\circ} \mathrm{C}$, respectively, by means of differential scanning calorimetry (DSC). The sheet specimens were solutiontreated at $740-900^{\circ} \mathrm{C}$ for $5-15 \mathrm{~min}$ in the $\beta$ single-phase region. They were cooled to $500^{\circ} \mathrm{C}$ in the $\alpha+\beta$ two-phase region at a cooling rate of $3.3^{\circ} \mathrm{C} \mathrm{min}^{-1}$ and held for $10 \mathrm{~min}$ at $500^{\circ} \mathrm{C}$, and then heated to $760-900^{\circ} \mathrm{C}$ at a heating rate of $10^{\circ} \mathrm{C} \mathrm{min}^{-1}$ and held for various periods, followed by quenching in water. Some specimens were subjected to CHT between 740 and $500{ }^{\circ} \mathrm{C}$ five times, instead of the single $\mathrm{CHT}$, before heating to the $\beta$ single-phase region. The procedure of heat treatment of the bars and sheets is illustrated in Fig. 1 and Supplementary Fig. 4.

Microstructural observation. The microstructure and the crystallographic features were investigated by optical microscopy and EBSD using a field emission scanning electron microscope. Method of determination of misorientation angle between subgrains is shown in Supplementary Fig. 1, and the accuracy of misorientation angle ${ }^{45}, 46$ is discussed in Supplementary Discussion.

Evaluation of grain size. The grain size of NGs and subgrains was evaluated by the linear intercept method using the optical micrographs. The length of a line segment drawn on the optical microscopy images, $L$, is described as follows:

$$
L=N \bar{l},
$$

where $N$ is the number of grains on the line segment and $\bar{l}$ is the average length of one grain. In three-dimensional (3D) grain growth ${ }^{13}$, a grain is taken as a sphere with a mean radius of $\bar{R}$ and the $\bar{l}$ is given by

$$
\bar{l}=\frac{4}{3} \bar{R},
$$

Thus, the average grain radius $\bar{R}$ is described using the Eqs. (6) and (7) as

$$
\bar{R}_{3 D}=\frac{3 L}{4 N}
$$




\section{Measurement of migration distance of grain boundaries. The sheet} specimens for determination of the GB migration distance for AGs were subjected to CHT using quartz capsules backfilled with $\mathrm{Ar}$ and quenched in water after holding for various periods at $800^{\circ} \mathrm{C}$. For the measurement of migration distance, the specimens etched after electropolishing were used and the GBs and sub-boundaries were observed using optical microscopy. Several AGs were observed in one specimen, but some grains probably started to grow after incubation. Therefore, the maximum width of the subgrain-free zone, i.e., the maximum distance between the subgrain region and the high-angle boundary, was defined as the migration distance. Once a growing AG faces another AG, the growth mode becomes NGG and the rate of GB migration becomes slow because the energy of subgrain boundaries has already been consumed. Therefore, the maximum migration distances of GBs of AGs that face subgrains were measured.

Superelastic tests. The superelasticity of $\mathrm{Cu}-\mathrm{Al}-\mathrm{Mn}$ single crystal bar $15.4 \mathrm{~mm}$ in diameter and $682 \mathrm{~mm}$ in length was evaluated by a tensile test at room temperature. The gauge length was $400 \mathrm{~mm}$ and the strain rate was $1.7 \times 10^{-4} \mathrm{~s}^{-1}$ The bar was first loaded to $1 \%$ strain and unloaded, and then the target strain was increased in $1 \%$ increments, each cycle being repeated twice.

Data availability. All relevant data are available from the corresponding author upon request.

Received: 18 April 2017 Accepted: 26 June 2017

Published online: 25 August 2017

\section{References}

1. Sutou, Y. et al. Effect of grain size and texture on pseudoelasticity in Cu-Al-Mnbased shape memory wire. Acta Mater. 53, 4121-4133 (2005).

2. Sutou, Y., Omori, T., Kainuma, R. \& Ishida, K. Grain size dependence of pseudoelasticity in polycrystalline $\mathrm{Cu}-\mathrm{Al}-\mathrm{Mn}$-based shape memory sheets. Acta Mater. 61, 3842-3850 (2013).

3. Ueland, S. M., Chen, Y. \& Schuh, C. A. Oligocrystalline shape memory alloys. Adv. Funct. Mater. 22, 2094-2099 (2012).

4. Patoor, E., Lagoudas, D. C., Entchev, P. B., Brinson, L. C. \& Gao, X. Shape memory alloys, part I: general properties and modeling of single crystals. Mech. Mater. 38, 391-429 (2006).

5. Sozinov, A., Likhachev, A. A., Lanska, N. \& Ullakko, K. Giant magnetic-fieldinduced strain in NiMnGa seven-layered martensitic phase. Appl. Phys. Lett. 80, 1746-1748 (2002).

6. Kainuma, R. et al. Magnetic-field-induced shape recovery by reverse phase transformation. Nature 439, 957-960 (2006).

7. Caron, P. \& Khan, T. Evolution of Ni-based superalloys for single crystal gas turbine blade applications. Aerosp. Sci. Technol. 3, 513-523 (1999).

8. Giamei, A. F. Development of single crystal superalloys: a brief history. Adv. Mater. Process. 171, 26-30 (2013).

9. Pollock, T. M. Alloy design for aircraft engines. Nat. Mater. 15, 809-815 (2016).

10. Mahajan, $\mathrm{S}$. The role of materials science in microelectronics: past, present and future. Prog. Mater. Sci. 49, 487-509 (2004).

11. Llorca, J. \& Orera, V. M. Directionally solidified eutectic ceramic oxides. Prog. Mater. Sci. 51, 711-809 (2006).

12. Reed R. C. The Superalloys: Fundamentals and Applications (Cambridge University Press, 2006).

13. Humphreys F. J. Recrystallization and Related Annealing Phenomena, 2nd edn. (Elsevier, 2004).

14. Frost, H. J., Thompson, C. V. \& Walton, D. T. Simulation of thin film grain structures-II. Abnormal grain growth. Acta Metall. Mater. 40, 779-793 (1992).

15. Hillert, M. On theory of normal and abnormal grain growth. Acta Metall. 13, 227-238 (1965)

16. Carpenter, H. C. H. \& Elam, C. F. The production of single crystals of aluminium and their tensile properties. Proc. R. Soc. Lond. A 100, 329-353 (1921).

17. Fujiwara, T. \& Hudita, T. A method of producing a long single crystal of aluminium drawn wire. J. Sci. Hiroshima Univ. A 8, 293-296 (1938).

18. Omori, T. et al. Abnormal grain growth induced by cyclic heat treatment. Science 341, 1500-1502 (2013).

19. Graesser, E. J. \& Cozzarelli, A. F. Shape-memory alloys as new materials for aseismic isolation. J. Eng. Mech. 117, 2590-2608 (1991).
20. Dolce, M., Cardone, D. \& Mametto, R. Implementation and testing of passive control devices on shape memory alloys. Earthq. Eng. Struct. Dyn. 29, 945-968 (2000).

21. Saiidi, M. S., Tazarv, M., Nakashoji, B., Varela, S. \& Kavianipour, F. Resilient and sustainable bridges of the future. Int. J. Bridge Eng. 3, 37-48 (2015).

22. Kainuma, R., Takahashi, S. \& Ishida, K. Thermoelastic martensite and shape memory effect in ductile Cu-Al-Mn alloys. Metall. Mater. Trans. A 27A, 2187-2195 (1996).

23. Araki, Y. et al. Potential of superelastic Cu-Al-Mn alloy bars for seismic applications. Earthq. Eng. Struct. Dyn. 40, 107-115 (2011).

24. Pareek, S. et al. Feasibility of externally activated self-repairing concrete with epoxy injection network and $\mathrm{Cu}-\mathrm{Al}-\mathrm{Mn}$ superelastic alloy reinforcing bars. Smart Mater. Struct. 23, 105027 (2014).

25. Araki, Y. et al. Shaking table tests of steel frame with superelastic $\mathrm{Cu}-\mathrm{Al}-\mathrm{Mn}$ SMA tension braces. Earthq. Eng. Struct. Dyn. 45, 297-314 (2016).

26. Horikawa, H., Ichinose, S., Morii, K., Miyazaki, S. \& Otsuka, K. Orientation dependence of $\beta_{1} \rightarrow \beta_{1}{ }^{\prime}$ stress-induced martensitic transformation in a Cu-AI-Ni alloy. Metall. Trans. A 19, 915-923 (1988).

27. Bhattacharya, K. \& Kohn, R. V. Symmetry, texture and the recoverable strain of shape-memory polycrystals. Acta Mater. 44, 529-542 (1996).

28. Šittner, P. \& Novák, V. Anisotropy of martensitic transformations in modeling of shape memory alloy polycrystals. Int. J. Plastic. 16, 1243-1268 (2000).

29. Kainuma, R., Satoh, N., Liu, X. J., Ohnuma, I. \& Ishida, K. Phase equilibria and Heusler phase stability in the $\mathrm{Cu}$-rich portion of the $\mathrm{Cu}-\mathrm{Al}-\mathrm{Mn}$ system. J. Alloys Compd. 266, 191-200 (1998).

30. Kusama, T. et al. Two- and three-dimensional grain growth in the $\mathrm{Cu}-\mathrm{Al}-\mathrm{Mn}$ shape memory alloy. Mater. Trans. 54, 2044-2048 (2013).

31. Nishizawa T. Thermodynamics of Microstructures (ASM International, 2008).

32. Sutou, Y., Koeda, N., Omori, T., Kainuma, R. \& Ishida, K. Effects of aging on stress-induced martensitic transformation in ductile $\mathrm{Cu}-\mathrm{Al}-\mathrm{Mn}$-based shape memory alloys. Acta Mater. 57, 5759-5770 (2009).

33. Murr L. E. Interfacial Phenomena in Metals and Alloys (Addison-Wesley, 1975).

34. Read W. T. Dislocations in Crystals (McGraw Hill, 1953).

35. Fisher, J. C. Calculation of diffusion penetration curves for surface and grain boundary diffusion. J. Appl. Phys. 22, 74-77 (1951).

36. Aaronson, H. I., Furuhara, T., Rigsbee, J. M., Reynolds, W. T. \& Howe, J. M. Crystallographic and mechanistic aspects of growth by shear and by diffusional processes. Metall. Trans. A 21, 2369-2409 (1990).

37. Luo, C. P. \& Weatherly, G. C. The Ineterphase boundary structure of precipitates in a Ni-Cr alloy. Philos. Mag. A 58, 445-462 (1988).

38. Furuhara, T., Wada, K. \& Maki, T. Atomic structure of interphase boundary enclosing bcc precipitate formed in fcc matrix in a Ni-Cr alloy. Metall. Mater. Trans. A 26, 1971-1978 (1995).

39. Ooishi, K., Yokota, S., Yasuda, K. \& Tsuji, Y. Development of $\beta$-brass single crystals and abnormal growth of crystal grains. J. Jpn Copper Brass Res. Assoc 32, 163-171 (1993)

40. Sugimoto, S., Okada, M. \& Homma, M. The enhancement of the magnetic properties of $\mathrm{Fe}-\mathrm{Cr}$-Co-Mo polycrystalline permanent magnet alloys by cold rolling and annealing. J. Appl. Phys. 63, 3707-3709 (1988).

41. Kaneko, H., Homma, M., Okada, M., Nakamura, S. \& Ikuta, N. FeCrCo ductile magnet with (BH)max=8MGOe. AIP Conf. Proc. 29, 620-621 (1976).

42. Sugimoto, S., Satoh, H., Okada, M. \& Homma, M. Evolution process of $<100>$ texture in Fe-Cr-Co-Mo permanent magnets. Mater. Trans. JIM 32, 557-561 (1991).

43. Omori, T. et al. Superelastic effect in polycrystalline ferrous alloys. Science $\mathbf{3 3 3}$ 68-71 (2011)

44. Omori, T., Iwaizako, H. \& Kainuma, R. Abnormal grain growth induced by cyclic heat treatment in Fe-Mn-Al-Ni superelastic alloy. Mater. Des. 101, 263-269 (2016)

45. Humphreys, F. J. \& Brough, I. High resolution electron backscatter diffraction with a field emission gun scanning electron microscope. J. Microsc. 195, 6-9 (1999).

46. Humphreys, F. J. Quantitative metallography by electron backscattered diffraction. J. Microsc. 195, 170-185 (1999).

\section{Acknowledgements}

This work was supported by the A-STEP program from the Japan Science and Technology Agency (JST) and by a Grant-in-Aid for Scientific Research from the Japan Society for the Promotion of Science (JSPS). We thank H. Kokawa, T. Furuhara, G. Miyamoto, K. Ishikawa and M. Fujii for helpful discussions. We also thank N. Yoshida for his invaluable assistance with the mechanical test.

\section{Author contributions}

T.K. determined the growth rate of abnormal grains and performed the EBSD analysis. T.S. determined the growth rate of subgrains. S.K. and T.T. carried out the heat treatment of the bars and the superelastic bending test. Y.A. performed the superelastic tensile test. 
T.K., T.O. and R.K. interpreted the data and wrote the manuscript. All the authors discussed the results and approved the manuscript.

\section{Additional information}

Supplementary Information accompanies this paper at doi:10.1038/s41467-017-00383-0.

Competing interests: The authors declare no competing financial interests.

Reprints and permission information is available online at http://npg.nature.com/ reprintsandpermissions/

Publisher's note: Springer Nature remains neutral with regard to jurisdictional claims in published maps and institutional affiliations. (c) (i) Open Access This article is licensed under a Creative Commons Attribution 4.0 International License, which permits use, sharing, adaptation, distribution and reproduction in any medium or format, as long as you give appropriate credit to the original author(s) and the source, provide a link to the Creative Commons license, and indicate if changes were made. The images or other third party material in this article are included in the article's Creative Commons license, unless indicated otherwise in a credit line to the material. If material is not included in the article's Creative Commons license and your intended use is not permitted by statutory regulation or exceeds the permitted use, you will need to obtain permission directly from the copyright holder. To view a copy of this license, visit http://creativecommons.org/ licenses/by/4.0/.

(C) The Author(s) 2017 